\title{
Agriculture Monitoring System Using IoT: A Review Paper
}

\section{Hafiz Saad Ahmad, Ali Hasnain}

\begin{abstract}
In recent years evolution of Internet of Things has brought revolution in many different sectors. The agriculture sector has become efficient and cost effective due to role of IoT. Monitoring systems has become the crucial part of agriculture. In past few years lot of work is been done and many systems has been purposed in this regard. In this paper we are going to make comparison between 4 different agriculture monitoring systems. We are also going to discuss what type of hardware including different sensors are used in those systems. We are also going to discuss software and platform on which those applications run. We will also discuss processing mechanism and what kind of algorithms are used in these systems and in the last we are going to make a comparative table based on these parameters.
\end{abstract}

Keywords - Internet of Things, Sensors, Microcontrollers, Agriculture Monitoring System.

\section{INTRODUCTION}

Agriculture is the fundamental source of source of revenue of people in all world. In history decade, it is found that there is not tons crop improvement in agriculture area. Food cost are constantly increasing because crop accuse is decline. It has pressed over 50 million people into deficiency due to the fact that 2010. There are variety of factors which might be chargeable for this, it may be due to water waste, low soil fertility, fertilizer abuse, weather alternate or diseases, and so on. It is very important to make successful involvement in agriculture and the answer is IOT in incorporation with Wireless sensor networks. It has possible to trade the manner of improvement in agriculture and offers high-quality contribution to make it smart agriculture. The IOT includes a 3-tier machine. It includes perception layer, system layer and relevance layer. Perception layer includes sensor motes. Information verbal exchange technology (ICT) enabled gadgets; sensor motes are constructing blocks of sensor era. It includes cameras, RFID tags, sensors and sensor network were acquainted with gadgets and amassing real time information. The network layer is a infrastructure of the IOT to understand time-honored carrier. It directs toward the mixture of the belief layer and alertness layer. The software layer is a layer that combines the IOT with the generation of precise industry. The IOT almost finished in all regions of enterprise, which incorporates smart agriculture, smart parking, smart constructing environmental monitoring, healthcare transportation and masses of more. Among them, agriculture is one of the vital regions which dreams hundreds of hundreds of human beings. Section 2 explains literature survey on shiny agriculture location. Section 3 some purposed smart agriculture model. The proposed methodology is discussed in section 5 and conclusion in section 6 .

\section{Related Work}

[1] focus on sensing and monitoring issues in agriculture and discusses different challenges and enabling technologies for sensing and monitoring in agriculture. [2] presented a review on different IoT devices and protocols and elaborated different issues and challenges faced during implementation of IoT in agriculture. [3] introduced a WSN framework and conducted experiments on soil moisture with 3 different frequencies. [4] review key technologies and frameworks of IoT in agriculture and IoT based architecture and its deployment related issues in agriculture sector and also discusses different application areas in agriculture. [5] discusses use of IoT in agriculture business and elaborated different sub areas where IoT can be applied. [6] performed survey on IoT and unmanned aerial vehicles used in agriculture. Elaborated different types of intelligent IoT sensors networks and protocols used in agriculture. [7] discusses different wireless sensor technologies and standards and future trends in agriculture and food industry. [8] performed a survey on implementation of automation in agriculture and discusses a system for watering, leaf and flower detection by using IoT. [9] introduced a WSN framework and conducted experiment on soil moisture with 3 different frequencies. [10] focus on different environmental parameters for increasing the quality of crops and also discusses different sensors and technologies available for agriculture. 


\section{Agriculture Monitoring Systems}

In this section we are going to discuss different agriculture monitoring systems which are purposed

\subsection{Precision Agriculture Monitoring System Using Green Internet of Things (G-IoT)}

Precision Agriculture (PA) as explain in [11] shown in fig 1, it's miles one of the promising technologies to boom the crop productiveness without affecting the product excellent. There are many technologies carried out inside the agricultural area the usage of (Internet of Things) IoT to boom the productiveness and overcome the existing demanding situations, which are; first, growth meals manufacture is needed to meet rising inhabitants and save you as of the hunger era. next, the lack in the numbers of labours because of civilization including a further mission into farming region, so to conquer these demanding situations need deploy farming structures mandatory neither occasion and labors nor human interference. Next is because of weather alternate and deprivation of water assets lead deploying some technology to assist to control the farmhouse water sources exactly. Fourth, reduce chemicals effect on human fitness is likewise required, by spraying those chemical compounds concerning of pesticide or fertilizer based totally at the crop needs in place of scheduled conventional method. Fifth, power accessibility and fee continues to be a wonderful venture within the agriculture area.

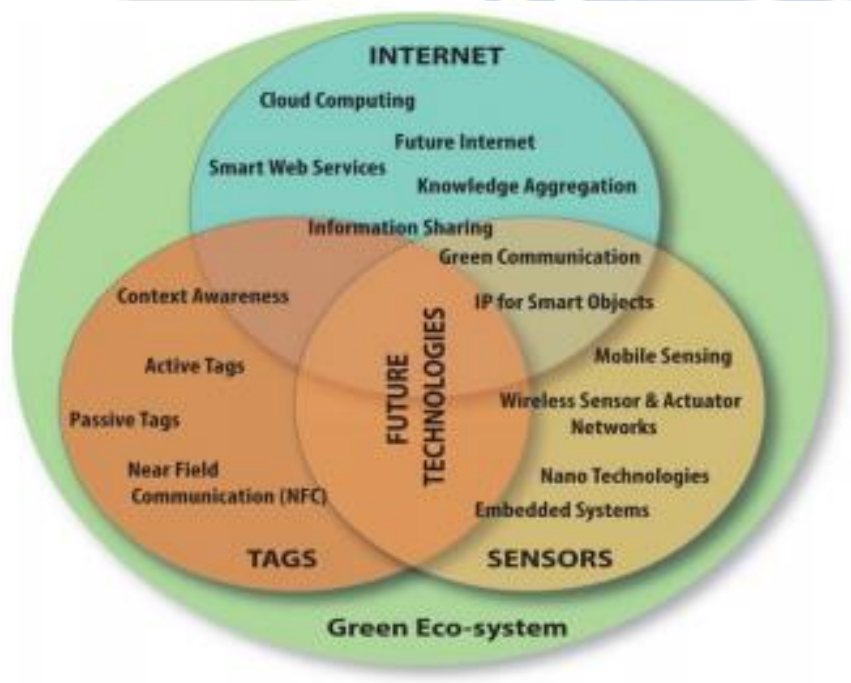

\subsection{IoT based monitoring system in smart agriculture}

[12] purposed a system (shown in fig 2) to improve the yield by agriculture. They used a CC3200 microcontroller having a WiFi and battery and connected to a network. Power system of the model has aspects of working, sub-system power is controlled by MCU, power of network processor in controlled automatically and chip level power is controlled by both i.e., MCU and network processor. This model uses a TMP007 temperature sensor which works in real time which mop up the energy of a body within a specified range i.e., 4-6 um. They used an efficient power supply mechanism which uses direct current into a $12 \mathrm{v}$ regulated voltage. System uses DMC to improve load efficiency and helps to meet requirement. HOC1010 was humidity sensor which was used to track moisture in air. MT9D111 was sensor which uses GPS system to send images to the receiver which are captured via camera.

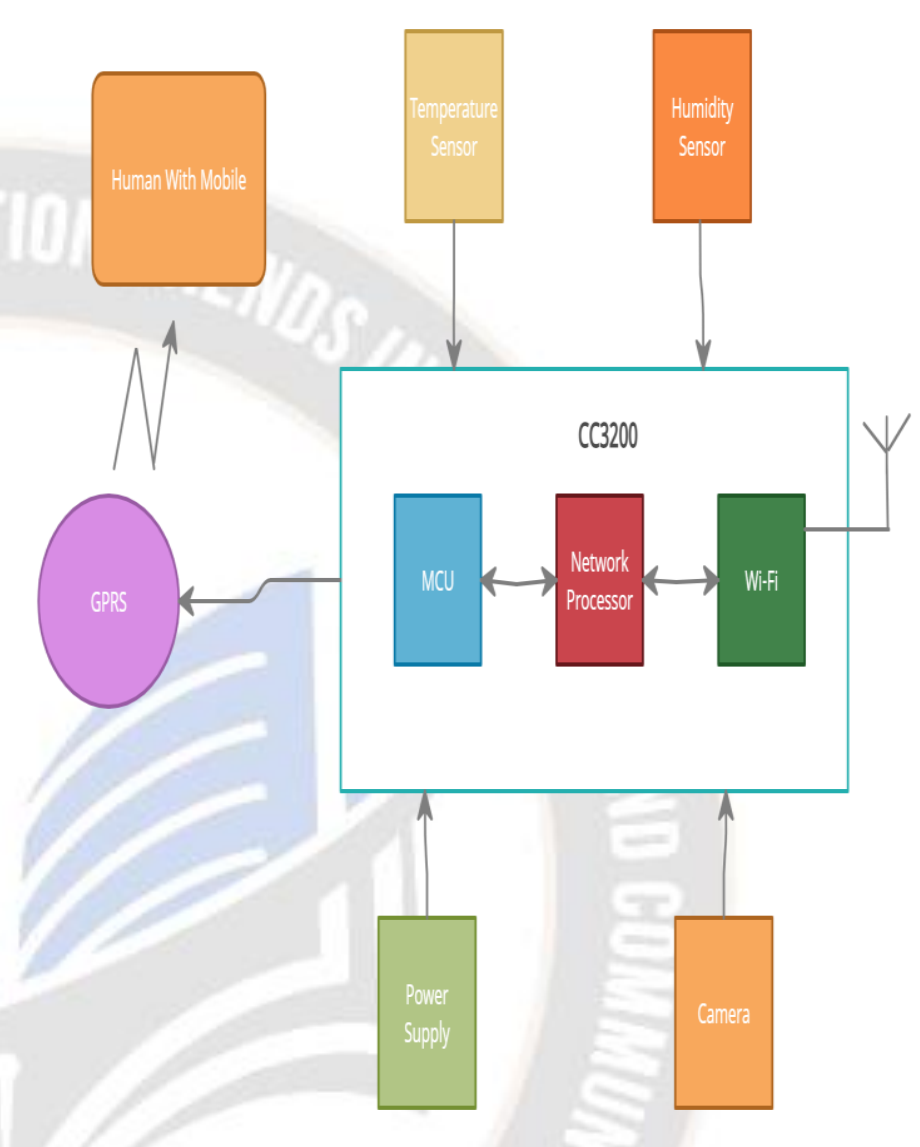

Fig 2: IoT based Monitoring System

\section{IoT based Smart Agriculture Monitoring System}

[13]The purposed a system which has two types a working mechanism i.e., automatic and manual. In automatic working the system switch on and off automatically when a specific value surpasses a specified threshold value and in manual working system switch on or off by user via android app through GPS. Data is received with threshold values, if data surpasses a typical value the system generates a warning and receiver receives this warning through software automatically and system is switch off after performing necessary instructions. GSM of system works on $900-1800 \mathrm{MHz}$ which can control any operating system and can work as a mobile device and uses a specified command to send a message to user through system terminal. Moisture sensor senses soil through short and open circuit mechanism working and output is displayed in the form of analog as well as in digital format. When the soil is wet the system displays output as 0 or vice versa. Temperature sensor LM35 is used which detects temperature in a range of -55 to $+150 \mathrm{C}$. PIR sensor is used to detect an object which works on by detecting IR emitted or 
reflected from a body.

\section{3}

An Agricultural Monitoring System Based on Wireless Sensor and Depth Learning Algorithm

these days, the assimilation of the IoT, shade computing provides a fair occasion used for the growth of agricultural information [14]. The modern function of agricultural IoT mostly focus on reserve consumption, environmental security, manufacture monitoring and produce traceability. Since the go round of the century, the bright authority system has been shaped based on conservatory measurement, greenhouse control and crop model [4]. From the perspective of plant physiology and thermodynamics, J.C. Bakker examined the variation in temperature, humidity, and $\mathrm{CO} 2$ awareness in conservatory [5]. Damas developed a disseminated remote control system for greenhouse auto Irrigation [6]. Evans and Bergman pioneer the have a look at of precision irrigation structures containing a self power controller, a linear movement tool, and a main pivot [7]. The agricultural IoT can be mixed with Zigbee to resolve the excessively enormous planting position and further defect in agricultural production. ZigBee [8] is an emerging quick-variety and low-strength wi-fi community generation, and a marker between wi-fi technology and Bluetooth era. Following a delegated verbal exchange preferred, ZigBee can realize lengthy-distance statistics transmission through the mutual coordination of heaps of wi-fi sensor nodes. The era is released and made by ZigBee Alliance. For the growth of the after that production ZigBee technology, the coalition be found in August 2001 [9] by four huge corporation, including the British company Invensys, Mitsubishi Electric Corporation, Motorola and the Dutch giant Philips Semiconductor Corporation. In September 2015, Chipcon delivered on world's first true System-on-Chip (SoC) ZigBee solution CC2430. Since then, more and more companies have developed their own ZigBee chips, applying ZigBee technology to wireless communication. Featuring low consumption, cheap rate, and short broadcast tempo, ZigBee has been broadly worn in medicinal care, manufacturing monitoring, ecological defense and a lot of further fields.

3.5An internet of things based agriculture monitoring system

The proposed gadget [15] includes IOT bases agriculture monitoring. The IOT is changing the agriculture manufacturing plus fixing the gigantic troubles or the principal challenge confronted through the farmers to days inside the meadow. The route accommodates of soil wetness sensor are insert in the soil to intellect whether or not the soil is wet or dry and a pi camera which permit to look at the sphere interest from the area in which we're. There need to be periodic reveal of the soil condition if the moisturizing level inside the soil is low and it is indicated to the relay unit that is connected to the motor transfer. It could be $\mathrm{ON}$ in dry circumstance and switch off the motor whilst the soil is in moist circumstance. The moisture stage of the soil is sensed by using the sensor inserted into the soil which gives sign to the raspberry pi circuit whether the earth desires wet or not.

Hardware used is

- Pi camera

Video stream of field action. All raspberry pi models far above the ground data speed pixel broadcast to the processer is possible through csi bus.

- Temp. and moisture sensor

- PIR sensor

It is capable of sensing motion

- De motor

Electrical motor converts electric energy into mechanic pumps, compressor and fan wheels.

- Algorithms.

Algorithms for live video streaming.

Algorithm for device operations.

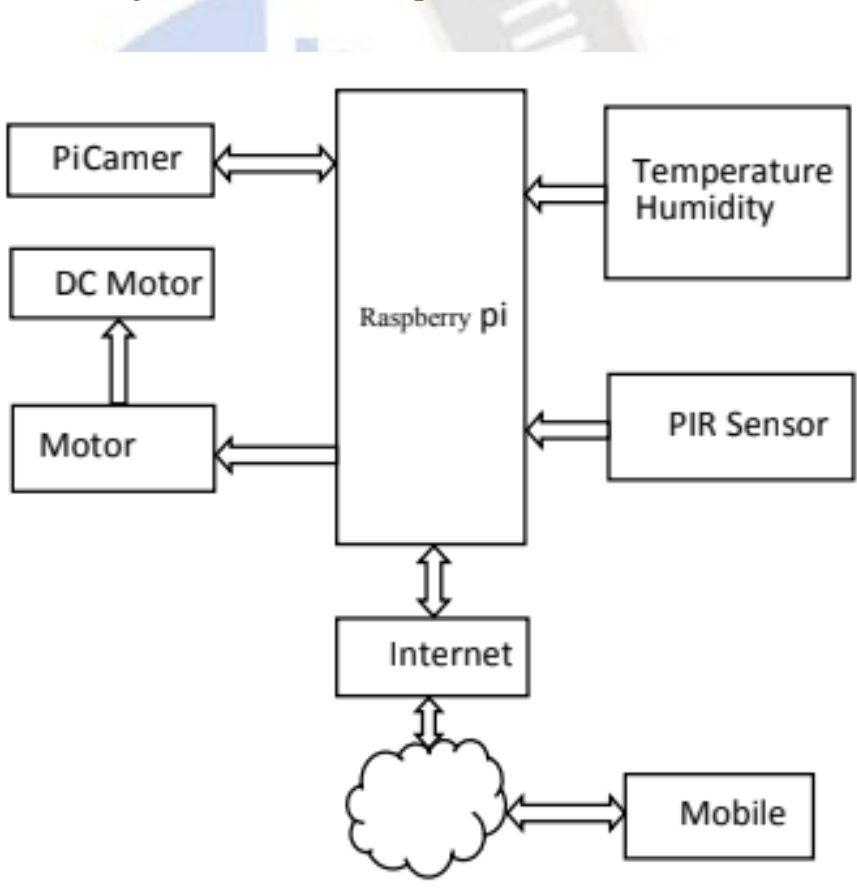

Fig 3: Purposed System Model

\subsection{Smart Agriculture Monitoring System using IoT}

[16] purposed a system which image processing technique to check to condition of crops and also to detect the moving objects. System uses a temperature and moisture sensors to exam the crops and inform about either the yield is ready to harvest or not. System uses a highly sensitive and powerful HR202 sensor to detect humidity in air and for safety measure uses a non-electric system to measure the level of water in the field. Use of IoT makes it easy to work with sensors and sharing data. LM35 sensor is used for temperature measurement and system precisely measure the change in 
temperature per minute depends on system requirement in what category to measure the temperature i.e., kelvin or Celsius. Fig 4 has shown the whole system. Water level in the field is measured in $\mathrm{cm}$ by using an indicator. When water level reaches a specified level, the whole system shut down automatically and data is sent to server through microcontrollers and output is displayed on an LCD.

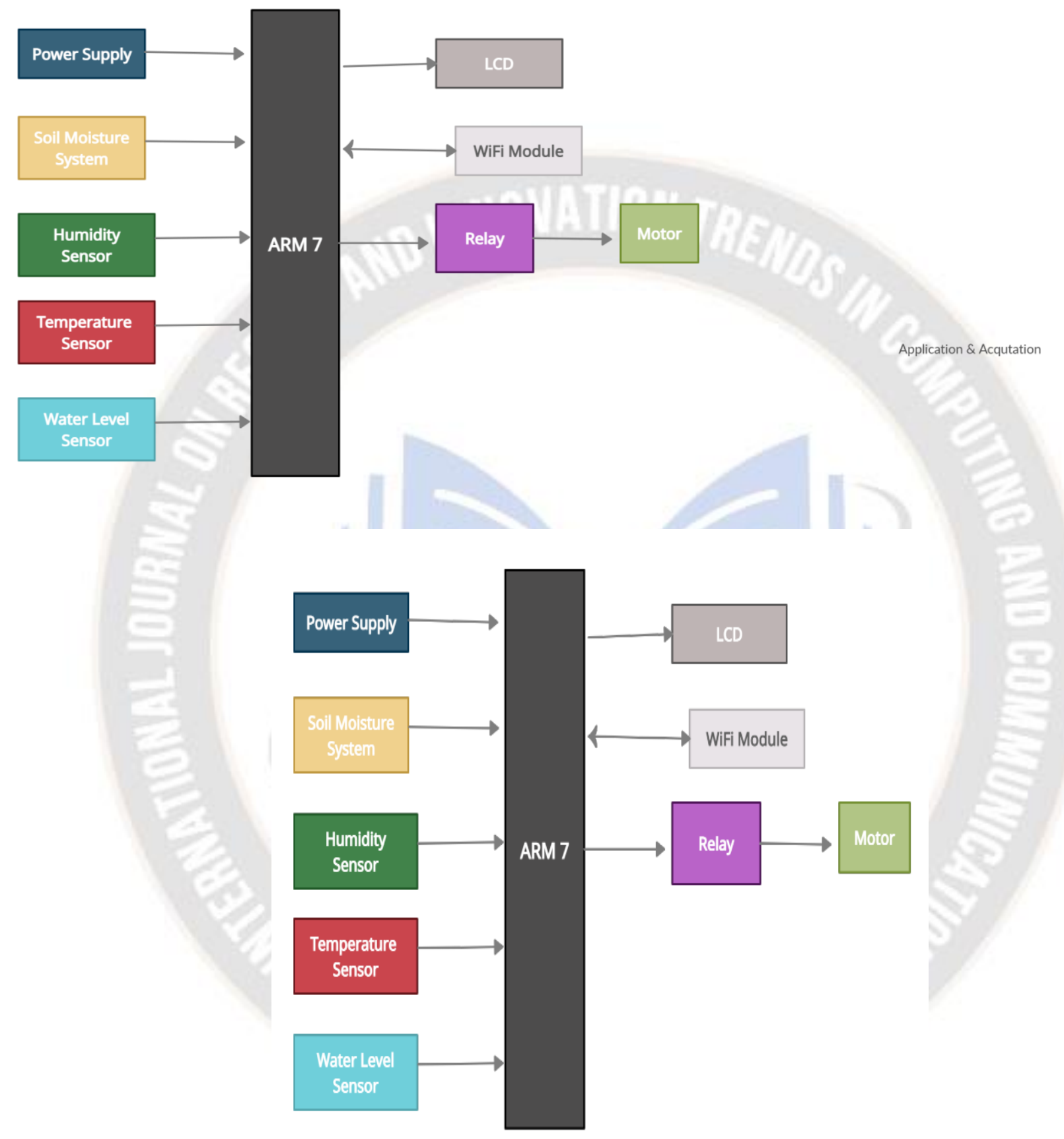

Fig 4: Diagram of Purposed system

\section{DISCUSSION}

With the advancements in internet of things and artificial intelligence, the new ways to improve the living standards are opened. Agriculture is the one of the areas where there is still need of improvements. Although researchers are doing work on developing new systems to benefit agriculture sector but they are not focusing on security as well as working mechanism of the systems. Different sub systems can be helpful in different ways. The temperature sensor can be used in such a way that it should detect only temperature of yield not all the living objects that are in the range of the system. To detect the moisture 2 different sensors should be used i.e., one for soil moisture detection and one used to detect moisture in the air, 
mostly researchers have focus on only one type i.e., either soil or air moisture detection. Image processing is the most important systems to monitor the crops, unfortunately most of the system does not elaborate any working regarding image processing. Data processing and security are the main concerns of any IoT systems but most of the researchers have not focused of these things. Still there are most of the areas where improvements can be making so it is on the researchers to focus on those areas so that there may be any improvement in the systems, which may be presented in future.

\section{CONCLUSION AND FUTURE WORK}

The analysis of different papers on Smart agriculture monitoring system have not discussed some of the major functionalities e.g., how to get access to that data, security etc. Most important one is security parameter as it concerns on data energy and data maintenance of the sensors and application itself. When if someone is going to design his/her "Internet of Things" application of any kind then these functionalities should be fulfilled. In future we will are going to purpose a model in which our main focus will be on all those functionalities as well as special focus on energy, data management and water management for irrigation system.

\section{References}

[1] Verdouw, Cor \& Wolfert, Sjaak \& Tekinerdogan, Bedir. (2016). Internet of Things in agriculture. CAB Reviews. 11. 1-12. 10.1079/PAVSNNR201611035.

[2] Sharma, Brij Bhushan, and Nagesh Kumar. "Internet of Things-Based Hardware and Software for Smart Agriculture: A Review." Proceedings of ICRIC 2019. Springer, Cham, 2020. 151-157.

[3] Yu, Xiaoqing, et al. "A survey on wireless sensor network infrastructure for agriculture." Computer Standards \& Interfaces 35.1 (2013): 59-64.

[4]Tegegne, Tesfa, Hailu Beshada Balcha, and Mebiratu Beyene. "Internet of Things Technology for Agriculture in Ethiopia: A Review." International Conference on Information and Communication Technology for Development for Africa. Springer, Cham, 2019.

[5] Rani, Deep, and Nagesh Kumar. "A Review of IoT Techniques and Devices: Smart Agriculture Perspective." Proceedings of ICRIC 2019. Springer, Cham, 2020. 113-123.

[6] Boursianis, Achilles D., et al. "Internet of Things (IoT) and Agricultural Unmanned Aerial Vehicles (UAVs) in Smart Farming: A Comprehensive Review." Internet of Things (2020): 100187.

[7] Ruiz-Garcia, Luis, et al. "A review of wireless sensor technologies and applications in agriculture and food industry: state of the art and current trends." sensors 9.6 (2009): 4728-4750.

[8] Jha, Kirtan, et al. "A comprehensive review on automation in agriculture using artificial intelligence." Artificial Intelligence in Agriculture 2 (2019): 1-12.

[9] Yu, Xiaoqing, et al. "A survey on wireless sensor network infrastructure for agriculture." Computer Standards \& Interfaces 35.1 (2013): 59-64.

[10] Thakur, Divyansh, et al. "Applicability of wireless sensor networks in precision agriculture: A review." Wireless Personal Communications 107.1 (2019): 471-512.

[11] Ali, Terteil AA, Viraj Choksi, and M. B. Potdar. "Precision agriculture monitoring system using green internet of things (g-iot)." 2018 2nd International Conference on Trends in Electronics and Informatics (ICOEI). IEEE, 2018.

[12] Prathibha, S. R., Anupama Hongal, and M. P. Jyothi. "IoT based monitoring system in smart agriculture." 2017 international conference on recent advances in electronics and communication technology (ICRAECT). IEEE, 2017.

[13] Suma, N., et al. "IOT based smart agriculture monitoring system." International Journal on Recent and Innovation Trends in computing and communication 5.2 (2017): 177-181.

[14] Geng, Liwei, and Tingting Dong. "An agricultural monitoring system based on wireless sensor and depth learning algorithm." International Journal of Online and Biomedical Engineering (iJOE) 13.12 (2017): 127-137.

[15] Boobalan, J., et al. "An IoT based agriculture monitoring system." 2018 International Conference on Communication and Signal Processing (ICCSP). IEEE, 2018.

[16] Jain, Aman, and Abhay Kumar. "Smart Agriculture Monitoring System Using IOT." (2019). 
International Journal on Recent and Innovation Trends in Computing and Communication

ISSN: 2321-8169 Volume: 9 Issue: 1

DOI: https://doi.org/10.17762/ijritcc.v9i1.5452

Article Received: 20 January 2021 Revised: 22 January 2021 Accepted: 27 January 2021 Publication: 31 January 2021

\section{Comparative Table of Agriculture Monitoring Systems}

\begin{tabular}{|c|c|c|c|c|c|}
\hline Paper & Hardware & Software & Algorithm & Advantages & Weakness \\
\hline [11] & $\begin{array}{l}\text { RFID's, Ultrasonic } \\
\text { Sensors, surveillance } \\
\text { cameras, database server } \\
\text { and microcontrollers }\end{array}$ & $\begin{array}{l}\text { Web Based } \\
\text { Application }\end{array}$ & $\begin{array}{l}\text { Regression Tree } \\
\text { Algorithm } \\
\text { Blob Detection } \\
\text { Algorithm }\end{array}$ & $\begin{array}{l}\text { Blob Detection } \\
\text { algorithm makes the pic } \\
\text { clear which helps the } \\
\text { system in processing to } \\
\text { images, } \\
\text { Use of ultrasonic sensors } \\
\text { increases the efficiency } \\
\text { of the system. }\end{array}$ & $\begin{array}{l}\text { Did not discusses the } \\
\text { security measured taken } \\
\text { to secure the system. } \\
\text { Only web base app makes } \\
\text { it difficult to access the } \\
\text { data when user wants. }\end{array}$ \\
\hline [12] & $\begin{array}{l}\text { CC3200 } \\
\text { microcontroller, } \\
\text { MT9D111 Camera } \\
\text { Sensor, TMP007 } \\
\text { Temperature Sensor, } \\
\text { HOC1010 Humidity } \\
\text { Sensor }\end{array}$ & Did not Specify & Did not Specify & $\begin{array}{l}\text { Well Design power } \\
\text { supply system to } \\
\text { efficient use of } \\
\text { electricity in system. } \\
\text { Sensors works at low } \\
\text { power which is increases } \\
\text { the life time of batteries. } \\
\text { Works by dealing with } \\
\text { real time data } \\
\text { communication. }\end{array}$ & $\begin{array}{l}\text { Did not discuss how to } \\
\text { handle data. } \\
\text { Security mechanism to } \\
\text { secure the system is not } \\
\text { discusses. } \\
\text { Working Mechanism is } \\
\text { not explained properly. } \\
\text { Did not discuss that haw } \\
\text { the user can access the } \\
\text { system. }\end{array}$ \\
\hline [13] & $\begin{array}{l}\text { PIC16F8774A } \\
\text { Microcontroller, LM34 } \\
\text { Temperature Sensor, } \\
\text { PIR Sensor, GSM } \\
\text { Module, EPP ROM }\end{array}$ & $\begin{array}{l}\text { Android } \\
\text { Application, } \\
\text { Proteus } 8\end{array}$ & Did not Specify & $\begin{array}{l}\text { System can be control } \\
\text { by manually as well as } \\
\text { automatically. } \\
\text { Generated data is easily } \\
\text { accessed by used } \\
\text { through mobile } \\
\text { application. }\end{array}$ & $\begin{array}{l}\text { Security measures are not } \\
\text { discussed in this paper. } \\
\text { PIR sensors are used } \\
\text { which are highly sensitive } \\
\text { so that they can be } \\
\text { interfered by external } \\
\text { objects easily. }\end{array}$ \\
\hline [14] & $\begin{array}{l}\text { Zigbee humidity sensor, } \\
\text { zigbee temperature } \\
\text { sensor, remote control, } \\
\text { antenna, terminal } \\
\text { control. }\end{array}$ & $\begin{array}{l}\text { Zigbee network } \\
\text { system }\end{array}$ & $\begin{array}{l}\text { Deep learning } \\
\text { algorithm }\end{array}$ & $\begin{array}{l}\text { Cheap cost and low } \\
\text { power consumption } \\
\text { Integrate the artificial } \\
\text { intelligence in } \\
\text { agriculture } \\
\text { modernization. }\end{array}$ & $\begin{array}{l}\text { Security measures are not } \\
\text { discussed in this paper. }\end{array}$ \\
\hline [15] & $\begin{array}{l}\text { Pi camera, temperature } \\
\text { and humidity sensors, } \\
\text { PIR sensor, DC motor. } \\
\text { Mobile. }\end{array}$ & $\begin{array}{l}\text { Android } \\
\text { application, } \\
\text { Raspberry pi }\end{array}$ & $\begin{array}{l}\text { Algorithms for } \\
\text { live video } \\
\text { streaming, } \\
\text { algorithm for } \\
\text { device operation. }\end{array}$ & $\begin{array}{l}\text { It is more efficient. } \\
\text { security of the system is } \\
\text { well. }\end{array}$ & $\begin{array}{l}\text { Only android base app } \\
\text { makes it difficult when } \\
\text { internet not working } \\
\text { properly. Security } \\
\text { measures are very less. }\end{array}$ \\
\hline [16] & $\begin{array}{l}\text { ARM7 Processor, LM35 } \\
\text { Temperature Sensor, HR } \\
202 \text { moisture detecting } \\
\text { sensor, Ball Level Water } \\
\text { Sensor }\end{array}$ & $\begin{array}{l}\text { Android and Web } \\
\text { Application }\end{array}$ & $\begin{array}{l}\text { self-developed } \\
\text { algorithm }\end{array}$ & $\begin{array}{l}\text { Data Can be accessed on } \\
\text { mobile devices. } \\
\text { Water sensor does not } \\
\text { require electricity so it is } \\
\text { safe to use. } \\
\text { Sensor used for } \\
\text { temperature and } \\
\text { moisture detection are } \\
\text { highly sensitive. } \\
\text { Use of Image Processing } \\
\text { technique for more } \\
\text { accurate results }\end{array}$ & $\begin{array}{l}\text { Did not specify what is } \\
\text { minimum threshold } \\
\text { value. } \\
\text { Security Mechanism is } \\
\text { not discussed. }\end{array}$ \\
\hline
\end{tabular}

